OPEN ACCESS

Edited by:

Amy L. Kenter,

University of Illinois at Chicago,

United States

Reviewed by:

Patricia Johanna Gearhart, National Institutes of Health (NIH),

United States

Javier Marcelo Di Noia, Institute of Clinical Research De

Montreal (IRCM), Canada

*Correspondence:

Heinz Jacobs

h.jacobs@nki.nl

Specialty section:

This article was submitted to

B Cell Biology,

a section of the journal

Frontiers in Immunology

Received: 27 November 2018

Accepted: 19 February 2019

Published: 12 March 2019

Citation:

Pilzecker B and Jacobs H (2019) Mutating for Good: DNA Damage

Responses During Somatic

Hypermutation

Front. Immunol. 10:438. doi: 10.3389/fimmu.2019.00438

\section{Mutating for Good: DNA Damage Responses During Somatic Hypermutation}

\author{
Bas Pilzecker and Heinz Jacobs* \\ Division of Tumor Biology \& Immunology, The Netherlands Cancer Institute, Amsterdam, Netherlands
}

Somatic hypermutation (SHM) of immunoglobulin (Ig) genes plays a key role in antibody mediated immunity. SHM in B cells provides the molecular basis for affinity maturation of antibodies. In this way SHM is key in optimizing antibody dependent immune responses. SHM is initiated by targeting the Activation-Induced Cytidine Deaminase (AID) to rearranged $V(D) J$ and switch regions of / g genes. The mutation rate of this programmed mutagenesis is $\sim 10^{-3}$ base pairs per generation, a million-fold higher than the non-AID targeted genome of B cells. AID is a processive enzyme that binds single-stranded DNA and deaminates cytosines in DNA. Cytosine deamination generates highly mutagenic deoxy-uracil $(U)$ in the DNA of both strands of the $/ g$ loci. Mutagenic processing of the $U$ by the DNA damage response generates the entire spectrum of base substitutions characterizing SHM at and around the initial $U$ lesion. Starting from the $U$ as a primary lesion, currently five mutagenic DNA damage response pathways have been identified in generating a well-defined SHM spectrum of $\mathrm{C} / \mathrm{G}$ transitions, $\mathrm{C} / \mathrm{G}$ transversions, and $A / T$ mutations around this initial lesion. These pathways include (1) replication opposite template $U$ generates transitions at $C / G$, (2) UNG2-dependent translesion synthesis (TLS) generates transversions at $\mathrm{C} / \mathrm{G}$, (3) a hybrid pathway comprising non-canonical mismatch repair (ncMMR) and UNG2-dependent TLS generates transversions at C/G, (4) ncMMR generates mutations at $A / T$, and (5) UNG2- and PCNA Ubiquitination (PCNA-Ub)-dependent mutations at A TT. Furthermore, specific strand-biases of SHM spectra arise as a consequence of a biased AID targeting, ncMMR, and anti-mutagenic repriming. Here, we review mammalian SHM with special focus on the mutagenic DNA damage response pathways involved in processing AID induced Us, the origin of characteristic strand biases, and relevance of the cell cycle.

Keywords: abasic site, base excision repair, cytosine deamination, DNA damage tolerance (DDT), non-canonical mismatch repair (ncMMR), translesion synthesis (TLS)

\section{INTRODUCTION}

Somatic hypermutation (SHM) occurs in antigen-activated germinal center B cells and contributes to antibody affinity maturation (1-8). Class switch recombination (CSR) involves a deletional rearrangement process within the immunoglobulin $(I g)$ heavy constant region, which enables B cells to switch the isotype of the clonotypic antibody, adapt its effector functions, and alter its tissue distribution (9-11). SHM and CSR are both initiated by the Activation-Induced Cytidine Deaminase (AID), which has a preference for targeting single-stranded DNA of rearranged Ig 
genes $(5,12-17)$. SHM correlates with transcription and promotor proximal transcriptionally active regions in immunoglobulin genes appear to be preferred targets of AID (18-22). AID deaminates cytosines in the DNA into deoxy-uracil (U) during the G1 phase of the cell cycle, though Us and abasic sites may persist into $S$ phase (23-25). AID activity and error-prone processing of the resulting $U$ increases the mutation rate in Ig genes by an estimated six orders of magnitude, specifically from $\sim 10^{-9}$ to $\sim 10^{-3}$ mutations per base pair per division (26-28). AID preferentially targets WRCY motif $(\mathrm{W}=\mathrm{A} / \mathrm{T}, \mathrm{R}=\mathrm{A} / \mathrm{G}$, and $\mathrm{Y}=\mathrm{C} / \mathrm{T})$. Another hotspot is the WA motif, though this motif is not targeted by AID (29-32). Five modes of mutagenic U processing are thought to be involved in generating the well-defined mutational spectrum of somatically mutated $I g$ genes (Figure 1) (1, 8, 33-37). SHM profiles comprise both transversions, where a pyrimidine base $(\mathrm{C}$ or $\mathrm{T}$ ) is substituted by a purine base (A or $\mathrm{G}$ ) or the reverse, and transitions, where a pyrimidine base $(\mathrm{C}$ or $\mathrm{T})$ or a purine base (A or $\mathrm{G}$ ) is replaced by the same class of base. In this review we discuss these modes, which are (1) replication opposite template U generates transitions at C/G, (2) UNG2 dependent translesion synthesis (TLS) generates transversions at C/G, (3) a hybrid pathway between non-canonical mismatch repair (ncMMR) and UNG2 dependent TLS generates transversions at $\mathrm{C} / \mathrm{G}$, (4) ncMMR generates mutations at $\mathrm{A} / \mathrm{T}$, and (5) UNG2 and PCNA Ubiquitination (PCNA-Ub) dependent mutations at A/T. Furthermore, the origin of tandem mutations, the characteristic strand biases, and cell cycle dependency of SHM are discussed. This review focuses on reports in mammalian systems. Findings in the DT40 lymphoma cell line have been reviewed elsewhere $(38,39)$.

\section{DNA DAMAGE RESPONSES INVOLVED IN SOMATIC HYPERMUTATION}

The DNA damage response plays a key role in SHM and takes advantage of defined components involved in DNA repair and DNA damage tolerance $(40,41)$. Here we will explain how these DNA damage repair and DNA damage tolerance pathways are repurposed to establish SHM pathways.

Normally, base modifications including Us in the DNA are efficiently recognized and repaired by the base excision repair (BER) pathway (42-44). To excise U from DNA backbone BER can use either one of four glycosylases, namely UNG, TDG, SMUG1, and MDB4 (45). However, only UNG was implicated in SHM (46). SMUG1 is downregulated in hypermutating B cells, though upon overexpression is able to rescue Ung-deficiency (47). Furthermore, SMUG1 was only found to have an effect on SHM and CSR in an Ung-deficient background (48). Initiating BER of Us, Uracil-(N)-glycosylase UNG recognizes and excises the irregular base from the sugar-phosphate backbone, creating an abasic site. At abasic sites the sugar phosphate backbone is intact. To further repair the abasic site, an incision is made beside the abasic site by AP-lyase APEX1 or APEX2 to yield a 3 ' hydroxyl adjacent and a 5 ' deoxyribose-phosphate (dRP). APEX2 is active in germinal center B cells, although it has a weaker AP-nuclease activity compared to APEX1 (4951). Subsequently, POLB processes the abasic site and fills in the single nucleotide gap. Finally, ligases LIG1 or LIG3 seal the $3^{\prime}$ hydroxyl and $5^{\prime}$ phosphate groups. This pathway is known as short patch BER. In contrast, long patch BER involves strand displacement synthesis by replicative polymerase POLD. In contrast to POLB, POLD requires the homotrimeric DNA clamp PCNA as a processivity factor. After the incision by an AP-lyase, strand displacement synthesis by POLD is followed by removal of the displaced single-stranded DNA flap by FEN1, and finally ligation by LIG1 completes long patch BER.

In addition to processing of $U$ by BER, the $U$ can also be recognized as a U-G mismatch and the mismatch can be repaired by mismatch repair (MMR) $(52,53)$. During replication, DNA polymerase errors can give rise to mismatches, which are recognized by the mismatch recognition complex MSH2/MSH6 $(52,54)$. MSH2/MSH6 is tethered to the replication fork in order to detect mismatches and initiate mismatch repair. Next, the endonuclease complex PMS2 and MLH1 can make an incision $5^{\prime}$ of the mismatch. This nick serves as an entry point for exonuclease EXO1, which by means of its $5^{\prime}$ to $3^{\prime}$ exonuclease activity creates a single-stranded gap, which normally is filled up by replicative polymerases (55-57). Next to the canonical replication-associated MMR, an alternative ncMMR pathway that is predominantly active during G1 has been identified (52, $53,58)$. ncMMR is thought to introduce mutations during SHM. During ncMMR, MSH2/MSH6 recognizes the AID induced $\mathrm{U}-\mathrm{G}$ mismatch. The incision is made by the PMS2 and M LH1 endonuclease complex $(53,58)$. Subsequently, exonuclease EXO1 generates a single-stranded gap, though EXO1 does not necessarily remove the $U$ containing strand. Next, the gap is filled in an error-prone manner by the translesion synthesis (TLS) polymerase POLH, a member of the Y-family of TLS DNA polymerases which lack proof-read activity $(52,53,58)$. Effective recruitment of POLH to the single-stranded gap depends on monoubiquitination of the DNA clamp PCNA at lysine residue K164 (PCNA-Ub) (59-61). By tethering DNA polymerases to the template, the homo-trimeric DNA clamp PCNA serves as a critical processivity factor of DNA polymerases.

To establish somatic mutations, TLS as part of the DNA damage tolerance system plays an important role during SHM. During TLS, specialized polymerases can continue DNA replication or DNA repair synthesis by inserting a nucleotide opposite of the lesion. During replication, TLS may occur at the replication fork to allow replication to continue or during the filling in of post replicative gaps. In this manner TLS is thought to prevent prolonged fork stalling or even a fork collapse $(62,63)$. When the replication fork or repair synthesis is stalled by an abasic site, PCNA is monoubiquitinated by ubiquitin ligase complex RAD6/RAD18 (59, 60, 64-66). The formation of PCNA-Ub is a key step in the recruitment of damage tolerant, error-prone TLS polymerases, where the PCNA interacting peptide (PIP) warrants specificity and the UBM or UBZ motif in TLS polymerases increase the affinity to PCNA. In addition, REV1 exerts an PCNA-K164 ubiquitination independent function 


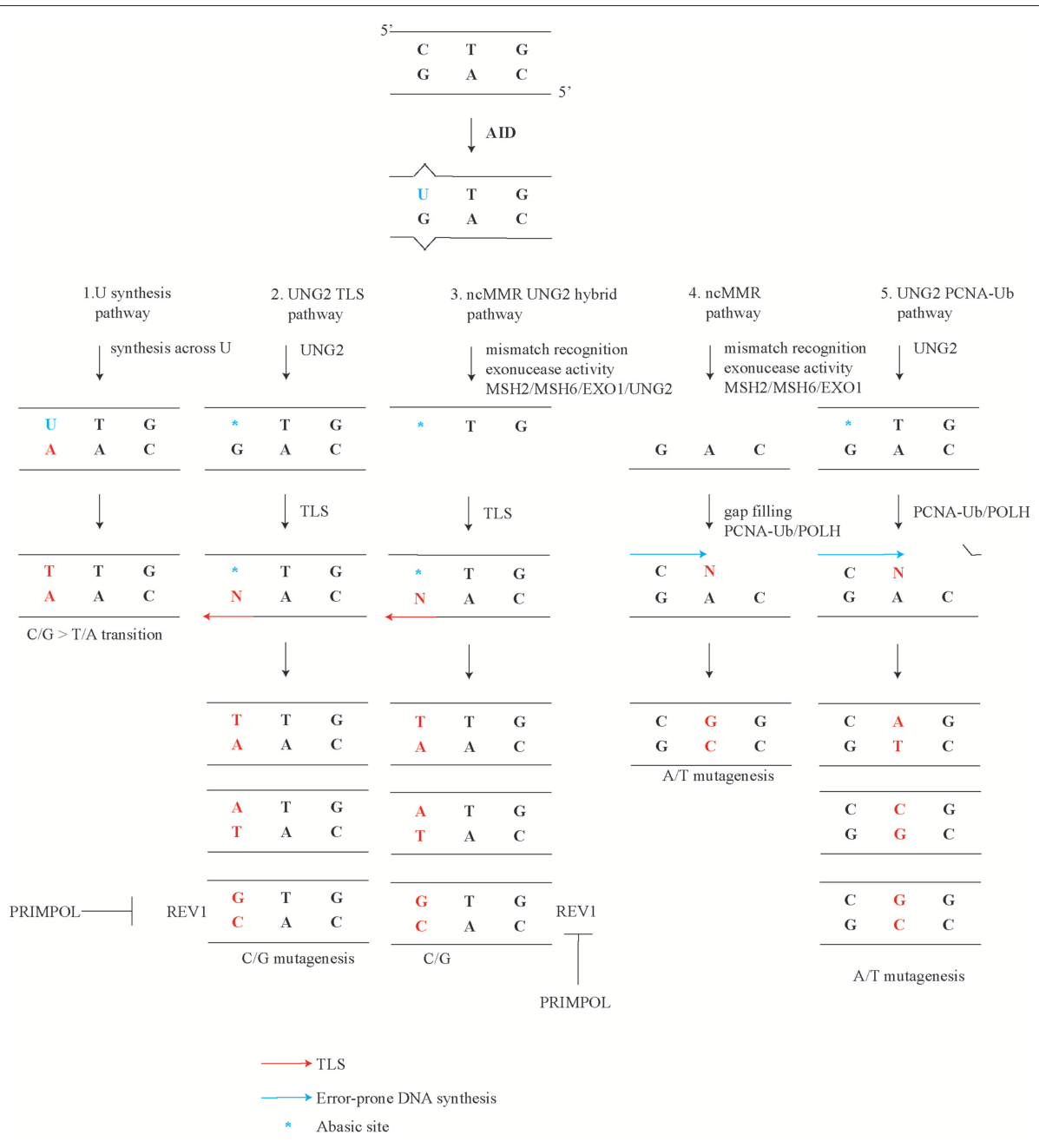

FIGURE 1 | Mutagenic pathways of SHM. Deamination of C by AID during SHM leads to a specific mutagenic spectrum. The creation of the full SHM spectrum depends on (1) replication opposite template $U$ instructs a template $T$ and generates transitions at C/G. (2) UNG2 dependent TLS generates C/G transversions. UNG2 converts a $U$ into an abasic site. As abasic sites are non-instructive, TLS opposite these sites generates both transitions and transversions. (3) Hybrid pathway between non-canonical mismatch repair (ncMMR) and UNG2 dependent TLS generates transversions at C/G. (4) ncMMR generates the majority of mutations at ATT. (5) UNG2- and PCNA Ubiquitination (PCNA-Ub)- dependent mutations at AT. This non-canonical long-patch BER pathway generates a minor but significant subset of AVT mutations ( 8\%).

by recruiting other TLS polymerases via its C-terminal region (67-69).

An alternative DNA damage tolerance mode involves repriming behind the fork stalling lesion by PRIMPOL (70-73). PRIMPOL activity is thought to be restricted to the leading strand while the replicative primase POL $\alpha$ primes continuously on the lagging strand $(73,74)$.

\section{REPLICATION OPPOSITE DEOXY-URACIL GENERATES C/G TRANSITIONS}

After $\mathrm{C}$ deamination by AID, DNA synthesis by any known DNA polymerase across the template $U$ creates a $C / G>T / A$ transition (Figure 1 point 1 ). If not recognized and processed by BER or MMR, the $U$ in the DNA template will because of its close similarity to a $\mathrm{T}$ instruct the insertion of an A opposite the $U(34,75)$. In line, in the absence of UNG2 and MSH2 or MSH6, Us remain and cannot be shunted into other mutagenic pathways (see below). Consequently, C/G transitions were found almost exclusively in this setting. The resulting SHM profile is considered as the DNA footprint of AID activity $(34,76)$.

\section{UNG2 DEPENDENT TRANSLESION SYNTHESIS CREATES C/G TRANSVERSIONS}

When a $\mathrm{U}$ is processed by $\mathrm{UNG}$, an abasic site is generated. As abasic sites are non-instructive, replication opposite this lesion generates both $\mathrm{C} / \mathrm{G}$ transversions and transitions (Figure 1, point 2) $(36,46,77)$. A strong decrease of $\mathrm{C} / \mathrm{G}$ transversions 
is observed in Ung deficient mice, however $\mathrm{C} / \mathrm{G}$ transitions are increased, suggesting that abasic sites are key intermediates in the generation of $\mathrm{C} / \mathrm{G}$ transversions $(36,46)$. Apparently, when Us are no longer processed into abasic sites, the increased number of Us leads to increased C/G transitions, as described above. There are two different splice variants produced from the Ung gene, mitochondrial localized UNG1 and nuclear localized UNG2 (78). As expected, only the nuclear isoform UNG2 was found relevant for $\operatorname{SHM}(79,80)$.

POLB has a central function in short patch BER. At present, the role of POLB during SHM remains controversial. Ex vivo analyzed B cells from transplanted fetal liver HSC and progenitors deficient for Polb did not affect SHM (81). In contrast, another study found Polb-deficiency to mildly suppress SHM and CSR (82). The different results may be explained by a variation in the methods. The latter study has isolated and cultured the B cells for 4 days before the analysis, while the first performed analysis immediately after harvesting germinal centers.

As abasic sites are non-instructive and stalling entities to replicative DNA polymerases, specialized TLS polymerases are recruited to bypass this lesion. The TLS polymerase REV1 was found to be able to tolerate abasic sites $(83,84)$. The structure of its active site only allows REV1 to insert dCMP $(85,86)$. As such, REV1 is considered a dCMP transferase rather than a genuine polymerase. Next to its transferase capacity, REV1 has a BRCT and a C-terminal domain; the latter can recruit other Yfamily members POLH, POLI, POLK (63). The inactivation of Rev1 selectively prevents C/G to G/C transversions, in line with the dCMP transferase activity of REV1 $(37,87)$. The N-terminal BRCT domain of REV1 is involved in binding PCNA and does not affect SHM $(88,89)$. Further studies have shown that the catalytic domain of REV1 is key for C/G > G/C transversions (90, 91). In addition, in the presence of a catalytically inactive REV1 the TLS polymerase POLH appears involved in the generation of $\mathrm{C} / \mathrm{G}>\mathrm{G} / \mathrm{C}$ transversions, though a Polh single mutant does not affect $C / G>G / C$ transversions (91). It seems that the TLS recruitment function of REV1 plays a very limited role in SHM, as the SHM profile is similar in the REV1 catalytic dead mutant compared to the full knock-out.

To date, it remains unknown which polymerases are involved in $\mathrm{G} / \mathrm{C}>\mathrm{T} / \mathrm{A}$ transversions, though in DT40 chicken lymphoma cell lines POLD3 as subunit of replicative polymerase delta has been suggested (92). This finding awaits corroboration in the mammalian system.

\section{HYBRID PATHWAY OF NON-CANONICAL MISMATCH REPAIR AND UNG2 DEPENDENT TRANSLESION SYNTHESIS GENERATES C/G TRANSVERSIONS}

Interestingly, about half of all $\mathrm{C} / \mathrm{G}$ transversions depend on the UNG2 and ncMMR hybrid pathway (Figure 1, point 3) $(36,37)$. In both the ncMMR dependent and independent arm, REV1 creates $\mathrm{C} / \mathrm{G}>\mathrm{G} / \mathrm{C}$ transversions (37). This raises the question regarding the difference between $\mathrm{C} / \mathrm{G}$ transversions relying only on UNG2 and those relying on both UNG2 and ncMMR. It has been suggested that $\mathrm{C} / \mathrm{G}$ transversions in the AID hot spot AGCW depend on UNG2 alone, while C/G transversions outside this motif rely both on UNG2 and ncMMR (93). The authors propose that the ncMMR dependent and independent $\mathrm{C} / \mathrm{G}$ transversions relate to the status of the cell cycle. How ncMMR and UNG2 cooperate to introduce $\mathrm{C} / \mathrm{G}$ transversions remains largely unaddressed. We proposed that ncMMR either creates single-stranded DNA substrate for AID, or additional Us and abasic were already present before excision. Consequently, Us are modified by UNG2 into abasic sites to generate $\mathrm{C} / \mathrm{G}$ transversions (36). The $\mathrm{U}$ on singlestranded DNA can be processed by UNG2 leading to $\mathrm{C} / \mathrm{G}$ transversions. UNG2 is around 1.7-fold more effective on single-stranded DNA as compared to double-stranded DNA and therefore the MMR-generated single-stranded gap may provide a preferred UNG2 substrate (94). Alternatively, there may be a mutagenic repair pathway involving both UNG2 and ncMMR. Biochemical studies indicated that such a pathway indeed exists and demonstrated that UNG2 is involved in resolving U-G mismatches in cooperation with ncMMR (95). As UNG2 itself cannot provide the nick, APEX2 instead can nick the DNA downstream of UNG2 during abasic site processing in germinal center B cells, as initially proposed (51). Further studies should reveal which of the above sources of abasic templates contribute to the generation of MSH2/UNG2 dependent $\mathrm{G} / \mathrm{C}$ transversions and the exact interplay between UNG2 and ncMMR.

\section{MUTAGENIC NON-CANONICAL MISMATCH REPAIR GENERATES A/T MUTATIONS}

Cytosine deamination by AID generates a U-G mismatch, which can be repaired by ncMMR (52). During SHM, more than ninety percent of all A/T mutations depends on ncMMR (Figure 1, point 4). Recognition of the $\mathrm{U}-\mathrm{G}$ mismatch requires the heterodimer MSH2/MSH6. The inactivation of Msh2 or Msh6 lead to impaired A/T mutagenesis $(36,75,96,97)$. Consistent with the single nucleotide mismatches generated by AID, the alternative mismatch recognition complex MSH2/MSH3 is not involved in $\mathrm{A} / \mathrm{T}$ mutagenesis during $\mathrm{SHM}$ as it recognizes only long insertion/deletion loops and mismatches involving multiple bases $(96,97)$. Unexpectedly, endonuclease complex PMS2/MLH1, which is involved in ncMMR by making the incision for exonuclease EXO1, has a very small to no effect on A/T mutagenesis (98-100). However, when Pms2 and Ung defective alleles are combined, the number of A/T mutations was found reduced to 50\%, suggesting that both PMS2 and UNG2 are involved in making the incision for the entry of EXO1 during ncMMR (24). After recognition of the mismatch, exonuclease EXO1 is key in generating single-stranded DNA patches (101). These gaps can be filled in by TLS polymerase POLH in an error-prone manner $(52,102,103)$. POLH is a highly errorprone polymerase with an in vitro error-rate of $10^{-1}$ to $10^{-2}$ mutations per base pair (104). Therefore, one would expect that 
it contributes to all mutation types during SHM. However, POLH has been shown to be preferentially error-prone at template TW motifs in vitro, explaining the contribution of POLH to A/T mutagenesis $(105,106)$. Interestingly, in vitro still one fourth of POLH induced mutations are $\mathrm{C} / \mathrm{G}$ mutations, although this is not reflected in Polh-deficient mouse models $(102,103,107)$. Another polymerase that does not have the same preference of POLH in mutating WA likely fills in the gap. Orthologs of POLH such as other members of the Y-family of polymerases REV1, POLK, and POLI may fill in the gap in absence of POLH. Indeed, the closest ortholog of POLH, POLK does contribute to $\mathrm{A} / \mathrm{T}$ mutagenesis in absence of POLH (108-110).

Effective recruitment of POLH to the EXO-1 generated single-stranded DNA is mediated by PCNA-Ub during SHM $(61,103)$. Hereafter, POLH fills the gap in an error-prone PCNA-Ub dependent manner $(61,102,103,111)$. PCNA K164 is ubiquitinated by the RAD6/RAD18 ubiquitin ligase E2/E3 complex $(59,112)$. Remarkably, a Rad18 defect had little to no effect on PCNA-Ub dependent A/T mutagenesis during SHM, as PCNA-Ub was decreased but still present (113). This is likely related to the existence of redundant E3-ligases, such as CRL4 ${ }^{\mathrm{Cdt} 2}$ or RNF8 (114-116).

Generally PCNA ubiquitination is associated with replication stalling, the question how PCNA is ubiquitinated during ncMMR during G1 remains. Like during $S$ phase, this may also be mediated by RPA coated single strand which recruit RAD6/RAD18.

In conclusion, ncMMR is key in generating the vast majority of $\mathrm{A} / \mathrm{T}$ mutations during SHM.

\section{UNG2 AND PCNA UBIQUITINATION DEPENDENT A/T MUTAGENESIS}

A minor but significant subset of $\mathrm{A} / \mathrm{T}$ mutations of about eight percent, is generated independently of ncMMR, although does depend on UNG2 and PCNA-Ub (Figure 1, point 5) $(36,117)$. Comparison of the mutation spectra from $U_{n g}^{-/-}$ and $P c n a^{K 164 R / K 164 R}$ single mutant to $U^{-1-} ; g^{-/ P n a} a^{K 164 R / K 164 R}$ double mutant germinal center $B$ cells revealed a further reduction of $\mathrm{A} / \mathrm{T}$ mutations (36). This observation suggests that long-patch BER involving PCNA-Ub also contributes to $\mathrm{A} / \mathrm{T}$ mutagenesis downstream of UNG2. Apparently, this non-canonical long patch BER has a minor but significant contribution to the generation of $\mathrm{A} / \mathrm{T}$ mutations. This finding is in line with the observation that in B cells $\mathrm{U}-\mathrm{G}$ mismatches and U-A base pairs are both mainly repaired by short patch BER (79). During both long-patch as well as short patch BER, APEX proteins are involved in the repair of abasic sites. Surprisingly, ubiquitously expressed APEX1 is downregulated while APEX2 is up-regulated in germinal center B cells (50, 51). Furthermore, Apex2-deficient B cells show a reduction of $\mathrm{A} / \mathrm{T}$ mutagenesis $(118,119)$. Our reanalysis of the mutation frequency instead of percentages revealed a $60-80 \%$ percent reduction of $\mathrm{A} / \mathrm{T}$ mutagenesis (Supplemental Table 1). Our reanalysis using mutation frequency instead of percentage of mutations revealed that $\mathrm{C} / \mathrm{G}$ transitions and transversions were also decreased, in both datasets. The general reduction of all mutation types in Apex2-deficient mice is in line with the conclusion drawn in Sabouri et al. The discrepancy stresses the importance of determining mutation profiles with frequencies instead of percentages. Since long patch BER only generates a minor proportion of $\mathrm{A} / \mathrm{T}$ mutagenesis, APEX2 is likely involved in the ncMMR pathway, for example by making incisions in the DNA which can be used by EXO1, as suggested previously (50, 51, 119) (Figure 2). Indeed, EXO1 is activated by a $5^{\prime}$ incision, a mismatch, and MSH2/MSH6 (120). In line, in vitro analysis of MMR and BER activity on a U-G mismatch containing plasmid demonstrated that an UNG2 dependent nick can be processed by EXO1 and MSH2/6 to effectuate MMR, independently of MLH1/PMS2 (95).

In summary, during SHM UNG2 and APEX2 contribute to the generation of a minor and a major part of $\mathrm{A} / \mathrm{T}$ mutations, respectively. The prime role of APEX2 in A/T mutagenesis may be to provide the nick for both ncMMR and long patch BER.

\section{TANDEM MUTATIONS}

Tandem mutations are two mutations in neighboring bases and around 5\% of all mutations are tandem mutations (121). These may arise through independent mutagenic events in the neighboring bases. However, analysis of SHM profiles revealed that tandem mutations are found more frequently than expected by chance $(121,122)$. Furthermore, a part of all tandem mutations rely on the presence of MSH2 or MSH6, POL $\zeta$ (REV3/REV7 complex), and POLI. Remarkably, both Poli- and POL $\zeta$ subunit Rev3-deficient $\mathrm{B}$ cells displayed a decrease in tandem mutations $(121,122)$. The mutation load in POL $\zeta$ subunit Rev3-defective B cells was lower. However, this may be due to an impaired proliferation rate in POL $\zeta$ subunit Rev3-defective B cells (123). It is reasoned that POLI fills the gap that is generated by EXO1 during ncMMR in an error prone manner. As POLI can generate mismatches but not extend efficiently from those, the mismatch provided by POLI is likely to be extended by POL $\zeta$ which subsequently generates the second mutation. POLH is also involved in ncMMr however, Polh-deficiency has no effect on tandem mutations $(121,122)$. These data suggested that during ncMMR predominantly POLH, but also POLI is involved in gap filling.

\section{MUTATIONAL STRAND BIASES OF SHM}

\section{AID Targeting and C/G Transition Bias}

AID targeting occurs on both the coding and the noncoding strand of $I g$ loci. Differential targeting of AID to these strands has been implicated with the C/G transition bias observed in Msh2;Ung double mutant, as well as Msh6;Ung and $P_{c n a}{ }^{K 164 R}$; Ung double mutant mice $(34,36,75,76)$. This $\mathrm{C} / \mathrm{G}$ transition bias consists of the 1.5-fold higher number of $\mathrm{C}>\mathrm{T}$ over $\mathrm{G}>\mathrm{A}$ in the coding strand. After nucleotide correction, $60 \%$ of all $\mathrm{C} / \mathrm{G}$ transitions arise on the coding strand and $40 \%$ on the non-coding strand (Figure 3A). This difference was considered to represent the AID targeting bias. Indeed as shown through measuring $\mathrm{U}$ content in the DNA, the amount of AID dependent 


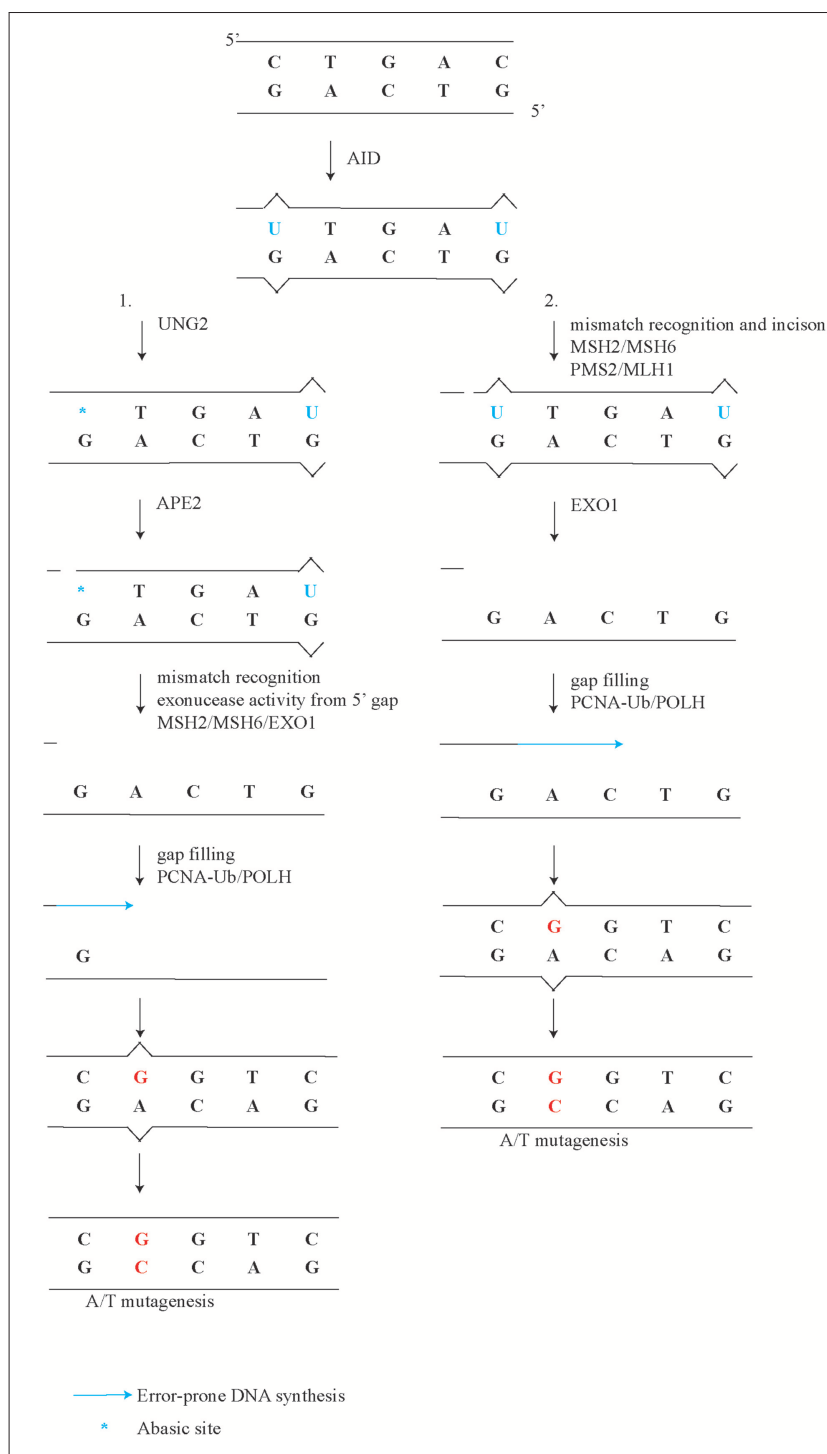

FIGURE 2 | Detailed model of ncMMR in A T mutagenesis. After $U$ induction by AID, UNG2 processes $U$ into an abasic site. In this more detailed model of ncMMR there are to arm on ncMMR, (1) UNG2 and APEX2 provide the incision for EXO1. EXO1 requires MSH2/6 and a 5' gap to the mismatch to be generate single-stranded DNA. PCNA-Ub recruits POLH, which can fill in the single-stranded DNA gap. (2) MSH2/MSH6 complex recognizes mismatch and activate the PMS2/MLH1 complex to make the incision. EXO1 creates singles stranded DNA gap, which is filled in by POLH.

$\mathrm{U}$ in the switch region are also $60 \%$ of Us are on the coding strand and $40 \%$ on the non-coding strand (124). AID is thought to target the single-stranded DNA of a transcription bubble of the coding strand, which is consistent with the $\mathrm{C}>\mathrm{T}$ over $\mathrm{G}>\mathrm{A}$ transition bias $(17,125)$. AID can also target DNA in DNA/RNA hybrids, G-structures, and supercoiled DNA which can all be found in transcribed genes (126-128). Differential distribution of these structures may contribute to the $\mathrm{C} / \mathrm{G}$ transition bias.

\section{A/T Mutation Bias}

Another strand bias found in SHM is the A/T bias, where in the coding strand A mutation are 2-fold more frequent than
T mutations (Figure 3B) $(33,129,130)$. As A/T mutagenesis is largely dependent on ncMMR pathway, it is likely that the $\mathrm{A} / \mathrm{T}$ bias involves the ncMMR pathway as well. During ncMMR, EXO1 creates single-stranded gap to remove the mismatch. Error-prone filling of the gap by POLH is likely the cause of the A mutations at template TW (131). As POLH is especially error-prone at TW templates giving rise to WA hotspots, for A mutations to arise, the non-coding strand is used as template by POLH, whereas for $\mathrm{T}$ mutations, the coding strand is used as template by POLH. This means that the coding strand contains the gaps more frequently than the non-coding strand. The difference in gap formation, suggests that the $U$ containing strand is removed, and that the AID targeting bias co-determines the $\mathrm{A} / \mathrm{T}$ bias. However, in $\mathrm{ncMMR}$ the $\mathrm{U}$ containing strand was found not to be targeted specifically when the U-G mismatch is repaired (53).

In order to gain more insight into the $\mathrm{A} / \mathrm{T}$ bias, a transgene containing a stretch of $A$ and $T$ with a $C$ or a $G$ in the middle was made (132). The analysis showed that the $C$ in the coding strand leads to an increase in $\mathrm{A} / \mathrm{T}$ mutagenesis in the surrounding of the $\mathrm{C}$. Whereas, a $\mathrm{G}$ in the coding strand leads to the suppression of A/T mutagenesis. The downstream mutation bias could be suppressed by impairing Msh2. This suggests that ncMMR is needed to induce the mutation bias, though the study has a limited amount of mutations analyzed. Strangely, MMR component PMS2 seems to counterbalance to the A/T bias, even though PMS2 does not affect the number of A/T mutations. Pms2-defective mice show an increased A/T bias, due to both an increase of A mutations and a decrease of $\mathrm{T}$ mutations $(24,133)$. The authors hypothesize about the existence of a MLH1/PSM2 dependent pathway and an UNG/APEX2 dependent mismatch repair pathway. According to this model, the MLH1/PMS2 mismatch pathway has no strand bias, but UNG/APEX2 dependent pathway does. The actual strand bias is proposed to be the result of averaging the amount of bias of both pathways. When the MLH1/PMS2 pathway is impaired, the increased activity of the APEX2 dependent pathway could lead to an increased strand bias. This model suggests that the location of the $\mathrm{U}$ dictates the A/T bias. Hereafter, UNG2 and APEX2 cooperate to provide the incision on the $U$ containing strand which is needed for EXO1 activity. As there are more Us found on the coding strand, there will be more EXO1 dependent singlestranded gaps on the coding strand, which lead to A mutations (Figure 3B) (124). This notion fits with the direction of the AID targeting bias and the A/T bias. Accordingly, one expects that an Apex2- or Ung-defect, would lead to a decreased strand bias. However, analysis of Ung-defective mice and our reanalysis of Apex 2 knock-out mice fail to demonstrate a decrease in the A/T bias $(24,118,119)$ (Supplemental Table 1).

Another model suggests that the A/T mutations arise though reverse transcriptase activity $(134,135)$. In line, POLH has been identified as DNA polymerase, RNA polymerase, and a reverse transcriptase (136-138). In fact, the reverse transcriptase activity of POLH has been implicated in A/T mutagenesis. However, potential POLH reverse transcriptase activity using the pre/mRNA as a template and the observed A/T strand bias are opposing each other, i.e., predict a higher amount of $\mathrm{T}$ rather 
A

\begin{tabular}{lllllllll} 
A & \multicolumn{10}{c}{ C $>$ T } \\
\hline T & U & T & G & U & U & G & A & A \\
A & G & A & C & G & G & C & T & T \\
\hline
\end{tabular}

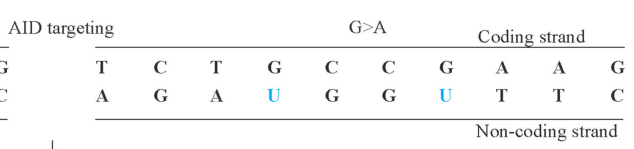

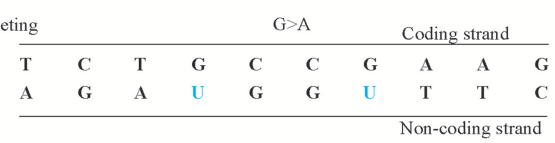

$\downarrow$ DNA synthesis

\begin{tabular}{llllllllll}
\hline T & U & T & G & U & U & G & A & A & G \\
A & A & A & C & A & A & C & T & T & C \\
\hline
\end{tabular}

\begin{tabular}{llllllllll}
\hline T & C & T & A & C & C & A & A & A & G \\
A & G & A & U & G & G & U & T & T & C
\end{tabular}

$\downarrow$ Total accumulated mutations

\begin{tabular}{|c|c|c|c|c|c|c|c|c|c|c|c|c|c|c|c|c|c|c|c|}
\hline$T$ & $\mathrm{~T}$ & $\mathrm{~T}$ & G & $\mathrm{T}$ & $\mathrm{T}$ & G & A & A & G & $\mathbf{T}$ & G & $T$ & $\mathbf{A}$ & $\mathbf{G}$ & C & A & $\mathbf{A}$ & A & G \\
\hline A & $\mathbf{A}$ & $\mathbf{A}$ & C & A & A & C & $T$ & $T$ & C & $\mathbf{A}$ & C & A & $\mathrm{T}$ & C & G & $T$ & $T$ & $T$ & C \\
\hline
\end{tabular}

B

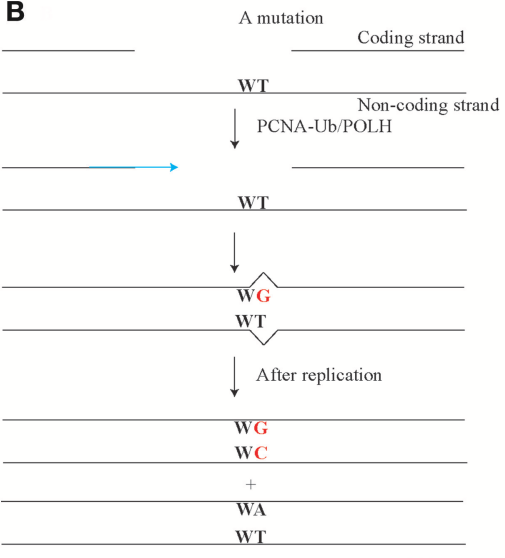

2 fold A mutations compared to T mutations
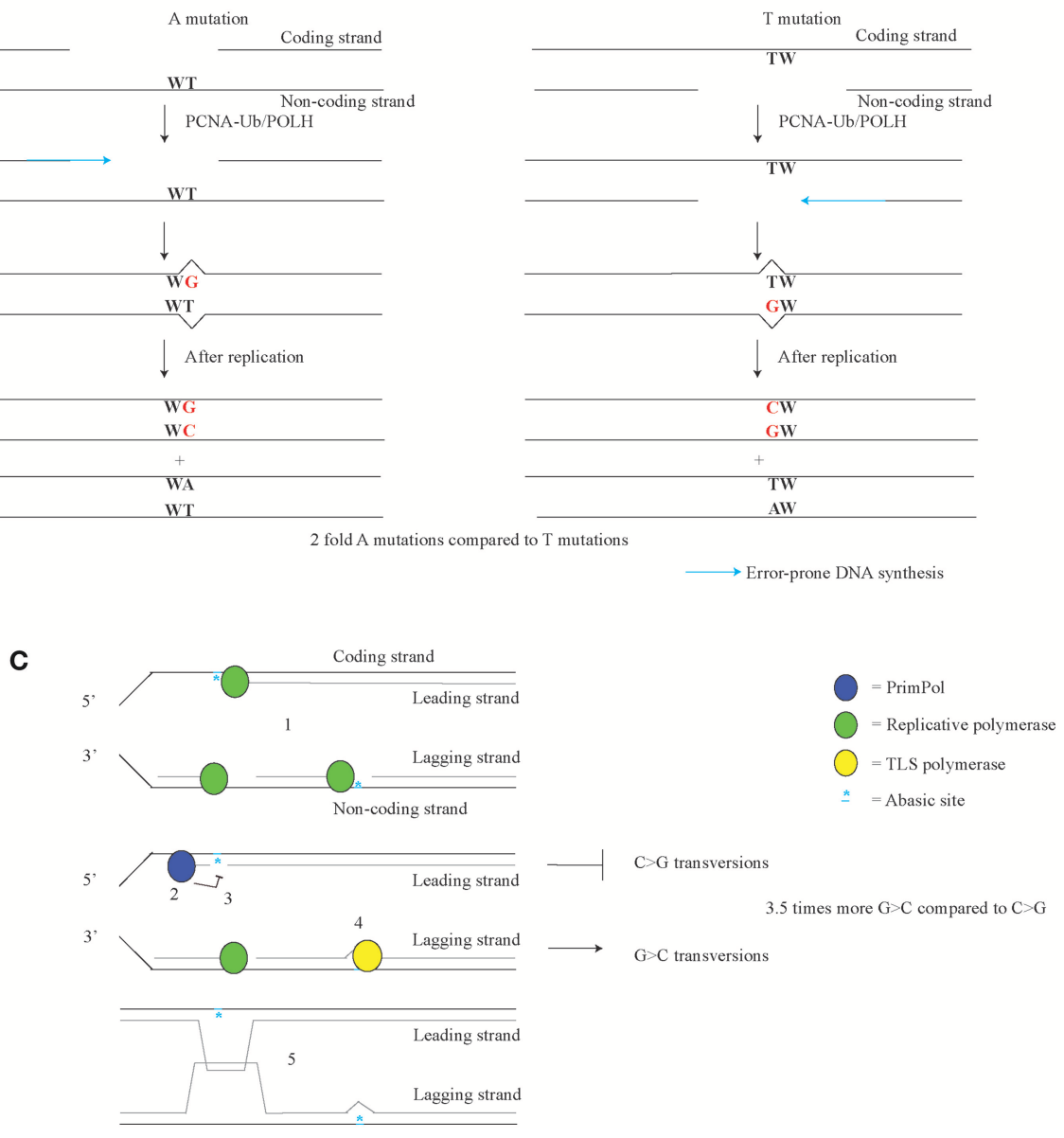

FIGURE 3 | Strand-biases in SHM. (A) AID targeting with a preference for the coding strand leads to a C/G transition strand bias. Us on the coding strand lead to $\mathrm{C}>\mathrm{T}$ transitions, while Us on the non-coding strand lead to a G>A transitions. (B) During error-prone mismatch repair, the MSH2/MSH6 complex recognizes the U-G mismatch, after which APEX2 or PMS2 provide the incisions for EXO1. POLH is especially error-prone on template TW. Therefore, the orientation of the gap made by EXO1 likely governs the ATT bias. (C) Replicative forks can be stalled on both leading and lagging strand by AID dependent abasic sites (1). After priming on the lagging strand, a replicative polymerase resumes DNA synthesis. PRIMPOL establishes G>C over C>G transversion bias found in Jh4 intron of the lgh gene, likely though anti-mutagenic activity on the leading strand of replication. PRIMPOL restarts by repriming after stalled DNA synthesis (2) and prevents TLS (3). On the lagging strand, TLS opposite of the abasic site leads to G>C mutations (4). PRIMPOL activity likely activates a homology driven error-free pathway such as template switching to prevent mutagenesis (5). (C) adapted from Pilzecker et al. (73).

than A mutations (Figure 4). The pre/mRNA is unlikely the source of $\mathrm{A} / \mathrm{T}$ mutagenesis, unless it involves RNA editing at A preferentially in WA motifs. A POLH mutation leading to a
POLH with an RNA or DNA specificity may provide the ultimate test, regarding the role of reverse transcription in SHM. However, involvement of RNA editing in A/T mutagenesis seems unlikely 


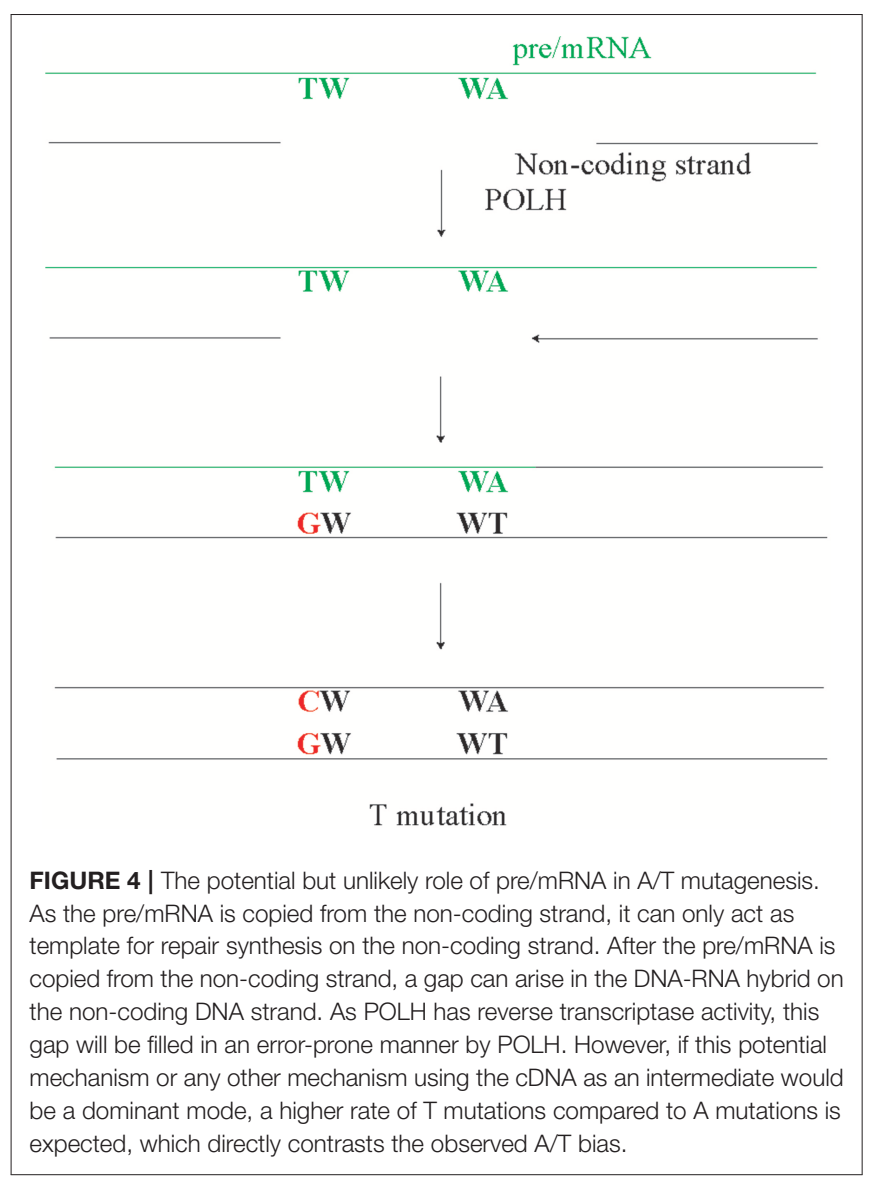

as A/T mutagenesis fully depends on AID and ncMMR, both of which target DNA.

In conclusion, the $\mathrm{A} / \mathrm{T}$ bias involves ncMMR activity and arises through POLH using the non-coding strand as template more frequently.

\section{G > C Over C> G Transversion Bias}

An additional bias found in $J h 4$ intronic region in SHM is the 3.5-fold higher frequency of $\mathrm{G}>\mathrm{C}$ over $\mathrm{C}>\mathrm{G}$ mutation bias (73). $\mathrm{C}>\mathrm{G}$ and $\mathrm{G}>\mathrm{C}$ mutations arise from abasic sites, which suggests that there is either and unequal number of abasic sites on the coding and non-coding strand, or there is a difference of antior pro-mutagenic DNA damage responses on the coding and non-coding strand. The $\mathrm{G}>\mathrm{C}$ over $\mathrm{C}>\mathrm{G}$ bias is governed by PRIMPOL, as Primpol-deficiency was found to increase $\mathrm{C}>\mathrm{G}$ transversions to the level of $\mathrm{G}>\mathrm{C}$ transversions (Figure 3C). Apparently, an anti-mutagenic activity of PRIMPOL prohibits C $>$ G transversions, which suggests that PRIMPOL exerts strandbiased anti-mutagenic activity at abasic sites. The dominant origin of replication in the Igh locus in B cells lies near the $3^{\prime}$ regulatory region enhancer (139-141). Therefore, most $\mathrm{C}>\mathrm{G}$ mutations are likely to arise from abasic sites on the leading strand, whereas most $\mathrm{G}>\mathrm{C}$ mutations arise from abasic sites on the lagging strand. Apparently, PRIMPOL has an antimutagenic activity on the leading strand (73). The notion that PRIMPOL acts as conservator of the genome is supported by the anti-mutagenic activity of PRIMPOL on AID family APOBEC induced mutagenesis in invasive breast cancer. In a genome wide setting, PRIMPOL anti-mutagenic activity on the leading strand on APOBEC dependent mutagenesis, would be expected. In line with this notion, an enrichment of APOBEC mutagenesis was actually found on the leading strand $(142,143)$.

Using purified PRIMPOL, it was demonstrated that this polymerase/primase is stalled at abasic site under nuclear conditions (70). Therefore, repriming by PRIMPOL has an important anti-mutagenic function. The anti-mutagenic function may be explained by redirecting DDT from error prone TLS to error-free homology-directed template switching. This has also been observed in yeast, where leading/lagging strand primase POL $\alpha$ has been shown to promote recombination directed template switching (144).

We propose a role for PRIMPOL during $S$ phase, despite the observation that AID is mainly active in G1 of the cell cycle, mainly using overexpression settings $(24,25)$. However, overexpression of AID outside of G1 is toxic to cells, therefore it is not possible to exclude S/G2 activity of AID in overexpression settings (145). Furthermore, $\mathrm{U}$ and abasic sites may persist into $\mathrm{S}$ phase. In addition, another study suggested that $\mathrm{C} / \mathrm{G}$ transitions and transversions can occur to some extend during $S$ phase (23).

In conclusion, the $\mathrm{G}>\mathrm{C}$ over $\mathrm{C}>\mathrm{G}$ transversion bias is established by the anti-mutagenic activity of PRIMPOL, where PRIMPOL likely reprimes behind abasic sites to stimulate error-free template switching. Strand biases in SHM are established by pro-mutagenic biases like the AID targeting and ncMMR, as well as anti-mutagenic activities, as the $\mathrm{G}>\mathrm{C}$ over $\mathrm{C}>\mathrm{G}$ PRIMPOL dependent mutation bias.

\section{CELL CYCLE REGULATION OF SOMATIC HYPERMUTATION}

AID is active during the G1 phase of the cells cycle $(25,145)$. Accordingly, G1 is also the cell cycle phase in which the highest levels of Us can be found in the immunoglobulin genes (25). Though, Us and abasic sites may persist into $S$ phases. Furthermore, expression of an AID modified to be specifically expressed in G1 provides all mutations characterizing SHM, whereas AID modified for S/G2/M expression does not support mutagenesis (24). Though, the lack of mutagenesis S/G2/M may be due to the toxicity of overexpressing AID during S phase (145). While most $\mathrm{A} / \mathrm{T}$ and $\mathrm{C} / \mathrm{G}$ mutagenesis has been suggested to be limited to G1, C/G transitions and transversions can occur during $S$ phase (23).

During G1, dNTP levels are very low. The low dNTP levels have been shown to impair A/T mutagenesis. Ribonucleotide reductase Samhd1 deficiency increases the concentration of nucleotides in G1 (146). Surprisingly, this led to a decrease of $\mathrm{A} / \mathrm{T}$ transversions, but not $\mathrm{A} / \mathrm{T}$ transitions. However, knocking out Samdh1 led to increased arrest in late G1, due to high nucleotide levels $(147,148)$. As AID is active in early G1, the 
late G1 arrest may affect the SHM profile independently of dNTP levels.

In conclusion, AID is active in G1. A/T and C/G mutations are generated primarily during $\mathrm{G} 1$, though a substantial fraction $\mathrm{C} / \mathrm{G}$ mutations may arise during $\mathrm{S}$ phase.

\section{CONCLUSION}

The discovery of AID laid the foundation in solving the molecular puzzle underlying SHM. Further detailed characterization uncovered distinct mutagenic pathways responsible in generating the typical mutation spectrum of somatically mutated Ig genes. Both, pro- and anti-mutagenic activities contribute in establishing defined strand preferences responsible for specific mutation biases recurrently found in these independently generated spectra. Many details regarding the transformation of faithful DNA damage response pathways into effective mutator pathways, often take advantage of errorprone DNA polymerases, as proposed in the Brenner \& Milstein model (149), now identified as members of the Y- family of TLS polymerases. At the same time insights from SHM studies fueled general mutation studies and provided novel insights into genome maintenance in general.

\section{REFERENCES}

1. Neuberger MS, Milstein C. Somatic hypermutation. Curr Opin Immunol. (1995) 7:248-54. doi: 10.1016/0952-7915(95)80010-7

2. Storb U, Peters A, Kim N, Shen HM, Bozek G, Michael N, et al. Molecular aspects of somatic hypermutation of immunoglobulin genes. Cold Spring Harb Sympos Quant Biol. (1999) 64:227-34. doi: 10.1101/sqb.1999.64.227

3. Kinoshita K, Honjo T. Linking class-switch recombination with somatic hypermutation. Nat Rev Mol Cell Biol. (2001) 2:493-503. doi: $10.1038 / 35080033$

4. Papavasiliou FN, Schatz DG. Somatic hypermutation of immunoglobulin genes: merging mechanisms for genetic diversity. Cell. (2002) 109(Suppl.) S35-44.

5. Seki M, Gearhart PJ, Wood RD. DNA polymerases and somatic hypermutation of immunoglobulin genes. EMBO Rep. (2005) 6:1143-8. doi: 10.1038/sj.embor.7400582

6. Maul RW, Gearhart PJ. AID and somatic hypermutation. Adv Immunol. (2010) 105:159-91. doi: 10.1016/S0065-2776(10)05006-6

7. McHeyzer-Williams M, Okitsu S, Wang N, McHeyzer-Williams L. Molecular programming of B cell memory. Nat Rev Immunol. (2011) 12:24-34. doi: $10.1038 / \mathrm{nri3} 128$

8. Di Noia JM, Neuberger MS. Molecular mechanisms of antibody somatic hypermutation. Ann Rev Biochem. (2007) 76:1-22. doi: 10.1146/annurev.biochem.76.061705.090740

9. Manis JP, Tian M, Alt FW. Mechanism and control of class-switch recombination. Trends Immunol. (2002) 23:31-9. doi: 10.1016/S1471-4906(01)02111-1

10. Stavnezer J, Guikema JE, Schrader CE. Mechanism and regulation of class switch recombination. Ann Rev Immunol. (2008) 26:261-92. doi: 10.1146/annurev.immunol.26.021607.090248

11. Xu Z, Zan H, Pone EJ, Mai T, Casali P. Immunoglobulin class-switch DNA recombination: induction, targeting and beyond. Nat Rev Immunol. (2012) 12:517-31. doi: 10.1038/nri3216

12. Muramatsu M, Sankaranand VS, Anant S, Sugai M, Kinoshita K, Davidson NO, et al. Specific expression of activation-induced cytidine deaminase (AID), a novel member of the RNA-editing deaminase

\section{AUTHOR CONTRIBUTIONS}

All authors listed have made a substantial, direct and intellectual contribution to the work, and approved it for publication.

\section{FUNDING}

Grants provided to $\mathrm{HJ}$ by the Netherlands Organization for Scientific Research (ZonMW Top 91213018 to HJ) and the Dutch Cancer Society (KWF NKI-2012-5243, KWF NKI-2016-10032, KWF NKI-2016-10796).

\section{ACKNOWLEDGMENTS}

The authors thank Prof $\mathrm{H}$. Te Riele for critical reading of the manuscript.

\section{SUPPLEMENTARY MATERIAL}

The Supplementary Material for this article can be found online at: https://www.frontiersin.org/articles/10.3389/fimmu. 2019.00438/full\#supplementary-material

family in germinal center B cells. J Biol Chem. (1999) 274:18470-6. doi: $10.1074 /$ jbc. 274.26 .18470

13. Muramatsu M, Kinoshita K, Fagarasan S, Yamada S, Shinkai Y, Honjo T. Class switch recombination and hypermutation require activation-induced cytidine deaminase (AID), a potential RNA editing enzyme. Cell. (2000) 102:553-63. doi: 10.1016/S0092-8674(00)00078-7

14. Petersen-Mahrt SK, Harris RS, Neuberger MS. AID mutates E. coli suggesting a DNA deamination mechanism for antibody diversification. Nature. (2002) 418:99-103.

15. Dickerson SK, Market E, Besmer E, Papavasiliou FN. AID mediates hypermutation by deaminating single stranded DNA. J Exp Med. (2003) 197:1291-6. doi: 10.1084/jem.20030481

16. Pham P, Bransteitter R, Petruska J, Goodman MF. Processive AIDcatalysed cytosine deamination on single-stranded DNA simulates somatic hypermutation. Nature. (2003) 424:103-7. doi: 10.1038/nature01760

17. Ramiro AR, Stavropoulos P, Jankovic M, Nussenzweig MC. Transcription enhances AID-mediated cytidine deamination by exposing singlestranded DNA on the nontemplate strand. Nat Immunol. (2003) 4:452-6. doi: $10.1038 /$ ni920

18. Peters A, Storb U. Somatic hypermutation of immunoglobulin genes is linked to transcription initiation. Immunity. (1996) 4:57-65. doi: 10.1016/S1074-7613(00)80298-8

19. Fukita Y, Jacobs H, Rajewsky K. Somatic hypermutation in the heavy chain locus correlates with transcription. Immunity. (1998) 9:105-14. doi: 10.1016/S1074-7613(00)80592-0

20. Jacobs H, Bross L. Towards an understanding of somatic hypermutation. Curr Opin Immunol. (2001) 13:208-18. doi: 10.1016/S0952-7915(00)00206-5

21. Bachl J, Carlson C, Gray-Schopfer V, Dessing M, Olsson C. Increased transcription levels induce higher mutation rates in a hypermutating cell line. J Immunol. (2001) 166:5051-7. doi: 10.4049/jimmunol.166.8.5051

22. Chaudhuri J, Tian M, Khuong C, Chua K, Pinaud E, Alt FW. Transcriptiontargeted DNA deamination by the AID antibody diversification enzyme. Nature. (2003) 422:726-30. doi: 10.1038/nature01574

23. Sharbeen G, Yee CW, Smith AL, Jolly CJ. Ectopic restriction of DNA repair reveals that UNG2 excises AID-induced uracils predominantly or exclusively during G1 phase. J Exp Med. (2012) 209:965-74. doi: 10.1084/jem.20112379 
24. Girelli Zubani G, Zivojnovic M, De Smet A, Albagli-Curiel O, Huetz F, Weill JC, et al. Pms2 and uracil-DNA glycosylases act jointly in the mismatch repair pathway to generate Ig gene mutations at A-T base pairs. J Exp Med. (2017) 214:1169-1180. doi: 10.1084/jem.20161576

25. Wang Q, Kieffer-Kwon KR, Oliveira TY, Mayer CT, Yao K, Pai J, et al. The cell cycle restricts activation-induced cytidine deaminase activity to early G1. J Exp Med. (2017) 214:49-58. doi: 10.1084/jem.20161649

26. Clarke SH, Huppi K, Ruezinsky D, Staudt L, Gerhard W, Weigert M. Inter- and intraclonal diversity in the antibody response to influenza hemagglutinin. J Exp Med. (1985) 161:687-704. doi: 10.1084/jem.161.4.687

27. Kleinstein SH, Louzoun Y, Shlomchik MJ. Estimating hypermutation rates from clonal tree data. J Immunol. (2003) 171:4639-49. doi: 10.4049/jimmunol.171.9.4639

28. Odegard VH, Schatz DG. Targeting of somatic hypermutation. Nat Rev Immunol. (2006) 6:573-83.

29. Rogozin IB, Kolchanov NA. Somatic hypermutagenesis in immunoglobulin genes. II. Influence of neighbouring base sequences on mutagenesis. Biochimica Biophys Acta. (1992) 1171:11-8.

30. Dorner T, Foster SJ, Farner NL, Lipsky PE. Somatic hypermutation of human immunoglobulin heavy chain genes: targeting of RGYW motifs on both DNA strands. Eur J Immunol. (1998) 28:3384-96. doi: 10.1002/(SICI)15214141(199810)28:10<3384::AID-IMMU3384>3.0.CO;2-T

31. Rogozin IB, Diaz M. Cutting edge: DGYW/WRCH is a better predictor of mutability at G:C bases in Ig hypermutation than the widely accepted RGYW/WRCY motif and probably reflects a two-step activation-induced cytidine deaminase-triggered process. J Immunol. (2004) 172:3382-4. doi: 10.4049/jimmunol.172.6.3382

32. Alvarez-Prado AF, Perez-Duran P, Perez-Garcia A, Benguria A, Torroja C, de Yebenes VG, et al. A broad atlas of somatic hypermutation allows prediction of activation-induced deaminase targets. J Exp Med. (2018) 215:761-71. doi: $10.1084 /$ jem. 20171738

33. Betz AG, Rada C, Pannell R, Milstein C, Neuberger MS. Passenger transgenes reveal intrinsic specificity of the antibody hypermutation mechanism: clustering, polarity, and specific hot spots. Proc Natl Acad Sci USA. (1993) 90:2385-8. doi: 10.1073/pnas.90.6.2385

34. Rada C, Di Noia JM, Neuberger MS. Mismatch recognition and uracil excision provide complementary paths to both Ig switching and the A/T-focused phase of somatic mutation. Mol Cell. (2004) 16:163-71. doi: 10.1016/j.molcel.2004.10.011

35. Neuberger MS, Di Noia JM, Beale RC, Williams GT, Yang Z, Rada C. Somatic hypermutation at A.T pairs: polymerase error versus dUTP incorporation. Nat Rev Immunol. (2005) 5:171-8.

36. Krijger PH, Langerak P, P.C. van den Berk, Jacobs H. Dependence of nucleotide substitutions on Ung2, Msh2, and PCNA-Ub during somatic hypermutation. J Exp Med. (2009) 206:2603-11.

37. Krijger PH, Tsaalbi-Shtylik A, Wit N, P.C. van den Berk, de Wind N, Jacobs $\mathrm{H}$. Rev1 is essential in generating $\mathrm{G}$ to $\mathrm{C}$ transversions downstream of the Ung2 pathway but not the Msh2+Ung2 hybrid pathway. Eur J Immunol. (2013) 43:2765-70.

38. Kothapalli N, Fugmann SD. Characterizing somatic hypermutation and gene conversion in the chicken DT40 cell system. Methods Mol Biol. (2011) 748:255-71. doi: 10.1007/978-1-61779-139-0_18

39. Abe T, Branzei D, Hirota K. DNA damage tolerance mechanisms revealed from the analysis of immunoglobulin $\mathrm{V}$ gene diversification in avian DT40 cells. Genes. (2018) 9:614. doi: 10.3390/genes9120614

40. Ciccia A, Elledge SJ. The DNA damage response: making it safe to play with knives. Mol Cell. (2010) 40:179-204. doi: 10.1016/j.molcel.2010.09.019

41. Giglia-Mari G, Zotter A, Vermeulen W. DNA damage response. Cold Spring Harb Perspect Biol. (2011) 3:a000745. doi: 10.1101/cshperspect.a0 00745

42. Lindahl T, DNA glycosylases, endonucleases for apurinic/apyrimidinic sites, and base excision-repair. Progr Nucleic Acid Res Mol Biol. (1979) 22:135-92.

43. David SS, O'Shea VL, Kundu S. Base-excision repair of oxidative DNA damage. Nature. (2007) 447:941-50. doi: 10.1038/nature 05978

44. Krokan HE, Bjoras M. Base excision repair. Cold Spring Harb Perspect Biol. (2013) 5:a012583. doi: 10.1101/cshperspect.a012583
45. Jacobs AL, Schar P. DNA glycosylases: in DNA repair and beyond. Chromosoma. (2012) 121:1-20. doi: 10.1007/s00412-011-0347-4

46. Rada C, Williams GT, Nilsen H, Barnes DE, Lindahl T, Neuberger MS. Immunoglobulin isotype switching is inhibited and somatic hypermutation perturbed in UNG-deficient mice. Curr Biol. (2002) 12:1748-55. doi: 10.1016/S0960-9822(02)01215-0

47. Di Noia JM, Rada C, Neuberger MS. SMUG1 is able to excise uracil from immunoglobulin genes: insight into mutation versus repair. EMBO J. (2006) 25:585-95. doi: 10.1038/sj.emboj.7600939

48. Dingler FA, Kemmerich K, Neuberger MS, Rada C. Uracil excision by endogenous SMUG1 glycosylase promotes efficient Ig class switching and impacts on A:T substitutions during somatic mutation. Eur J Immunol. (2014) 44:1925-35. doi: 10.1002/eji.201444482

49. Burkovics P, Szukacsov V, Unk I, Haracska L. Human Ape2 protein has a 3'-5' exonuclease activity that acts preferentially on mismatched base pairs. Nucleic Acids Res. (2006) 34:2508-15. doi: 10.1093/nar/gkl259

50. Guikema JE, Linehan EK, Tsuchimoto D, Nakabeppu Y, Strauss PR, Stavnezer J, et al. APE1- and APE2-dependent DNA breaks in immunoglobulin class switch recombination. J Exp Med. (2007) 204:3017-26. doi: 10.1084/jem.20071289

51. Schrader CE, Guikema JE, Wu X, Stavnezer J. The roles of APE1, APE2, DNA polymerase beta and mismatch repair in creating $S$ region DNA breaks during antibody class switch. Philos Trans R Soc London Series B Biol Sci. (2009) 364:645-52. doi: 10.1098/rstb.2008.0200

52. Wilson TM, Vaisman A, Martomo SA, Sullivan P, Lan L, Hanaoka F, et al. MSH2-MSH6 stimulates DNA polymerase eta, suggesting a role for A:T mutations in antibody genes. J Exp Med. (2005) 201:637-45. doi: $10.1084 /$ jem. 20042066

53. Pena-Diaz J, Bregenhorn S, Ghodgaonkar M, Follonier C, ArtolaBoran M, Castor D, et al. Noncanonical mismatch repair as a source of genomic instability in human cells. Mol Cell. (2012) 47:669-80. doi: 10.1016/j.molcel.2012.07.006

54. Kunkel TA, Erie DA. Eukaryotic Mismatch Repair in Relation to DNA Replication. Ann Rev Genet. (2015) 49:291-313. doi: 10.1146/annurev-genet-112414-054722

55. Modrich P, Lahue R. Mismatch repair in replication fidelity, genetic recombination, and cancer biology. Ann Rev Biochem. (1996) 65:101-33. doi: 10.1146/annurev.bi.65.070196.000533

56. Kolodner RD, Marsischky GT. Eukaryotic DNA mismatch repair. Curr Opin Genet Dev. (1999) 9:89-96. doi: 10.1016/S0959-437X(99)80013-6

57. Jiricny J, The multifaceted mismatch-repair system. Nat Rev Mol Cell Biol. (2006) 7:335-46.

58. Zlatanou A, Despras E, Braz-Petta T, Boubakour-Azzouz I, Pouvelle C, Stewart GS, et al. The hMsh2-hMsh6 complex acts in concert with monoubiquitinated PCNA and Pol eta in response to oxidative DNA damage in human cells. Mol Cell. (2011) 43:649-62. doi: 10.1016/j.molcel.2011. 06.023

59. Hoege C, Pfander B, Moldovan GL, Pyrowolakis G, Jentsch S. RAD6dependent DNA repair is linked to modification of PCNA by ubiquitin and SUMO. Nature. (2002) 419:135-41. doi: 10.1038/nature00991

60. Stelter P, Ulrich HD. Control of spontaneous and damage-induced mutagenesis by SUMO and ubiquitin conjugation. Nature. (2003) 425:18891. doi: $10.1038 /$ nature 01965

61. Langerak P, Nygren AO, Krijger PH, van den Berk PC, Jacobs H. A/T mutagenesis in hypermutated immunoglobulin genes strongly depends on PCNAK164 modification. J Exp Med. (2007) 204:1989-98. doi: $10.1084 /$ jem.20070902

62. Friedberg EC, DNA damage and repair. Nature. (2003) 421:436-40.

63. Sale JE, Lehmann AR, Woodgate R. Y-family DNA polymerases and their role in tolerance of cellular DNA damage. Nature reviews. Mol Cell Biol. (2012) 13:141-52. doi: 10.1038/nrm3289

64. Watanabe K, Tateishi S, Kawasuji M, Tsurimoto T, Inoue H, Yamaizumi M. Rad18 guides poleta to replication stalling sites through physical interaction and PCNA monoubiquitination. EMBO J. (2004) 23:3886-96. doi: 10.1038/sj.emboj.7600383

65. Ulrich HD, The RAD6 pathway: control of DNA damage bypass and mutagenesis by ubiquitin and SUMO. Chembiochem. (2005) 6:1735-43. 
66. Zhang H, Lawrence CW. The error-free component of the RAD6/RAD18 DNA damage tolerance pathway of budding yeast employs sisterstrand recombination. Proc Natl Acad Sci USA. (2005) 102:15954-9. doi: $10.1073 /$ pnas. 0504586102

67. Guo C, Fischhaber PL, Luk-Paszyc MJ, Masuda Y, Zhou J, Kamiya K, et al. Mouse Rev1 protein interacts with multiple DNA polymerases involved in translesion DNA synthesis. EMBO J. (2003) 22:6621-30. doi: 10.1093/emboj/cdg626

68. Ohashi E, Murakumo Y, Kanjo N, Akagi J, Masutani C, Hanaoka F, et al. Interaction of hREV1 with three human Y-family DNA polymerases. Genes Cells. (2004) 9:523-31. doi: 10.1111/j.1356-9597.2004.00747.x

69. Tissier A, Kannouche P, Reck MP, Lehmann AR, Fuchs RP, Cordonnier A. Co-localization in replication foci and interaction of human Y-family members, DNA polymerase pol eta and REVl protein. DNA Repair. (2004) 3:1503-14. doi: 10.1016/j.dnarep.2004.06.015

70. Bianchi J, Rudd SG, Jozwiakowski SK, Bailey LJ, Soura V, Taylor E, et al. PrimPol bypasses UV photoproducts during eukaryotic chromosomal DNA replication. Mol Cell. (2013) 52:566-73. doi: 10.1016/j.molcel.2013.10.035

71. Garcia-Gomez S, Reyes A, Martinez-Jimenez MI, Chocron ES, Mouron S, Terrados G, et al. PrimPol, an archaic primase/polymerase operating in human cells. Mol Cell. (2013) 52:541-53. doi: 10.1016/j.molcel.2013.09.025

72. Mouron S, Rodriguez-Acebes S, Martinez-Jimenez MI, Garcia-Gomez S, Chocron S, Blanco L, et al. Repriming of DNA synthesis at stalled replication forks by human PrimPol. Nat Struc Mol Biol. (2013) 20:1383-9. doi: $10.1038 / \mathrm{nsmb} .2719$

73. Pilzecker B, Buoninfante OA, Pritchard C, Blomberg OS, Huijbers IJ, van den Berk PC, et al. PrimPol prevents APOBEC/AID family mediated DNA mutagenesis. Nucleic Acids Res. (2016) 44:4734-44. doi: 10.1093/nar/gkw123

74. Baker TA, Bell SP. Polymerases and the replisome: machines within machines. Cell. (1998) 92:295-305. doi: 10.1016/S0092-8674(00)80923-X

75. Xue K, Rada C, Neuberger MS. The in vivo pattern of AID targeting to immunoglobulin switch regions deduced from mutation spectra in msh2-/ung-/- mice. J Exp Med. (2006) 203:2085-94. doi: 10.1084/jem.20061067

76. Shen HM, Tanaka A, Bozek G, Nicolae D, Storb U. Somatic hypermutation and class switch recombination in Msh6(-/-)Ung(-//) double-knockout mice. J Immunol. (2006) 177:5386-92. doi: 10.4049/jimmunol.177.8.5386

77. Di Noia J, Neuberger MS. Altering the pathway of immunoglobulin hypermutation by inhibiting uracil-DNA glycosylase. Nature. (2002) 419:438. doi: 10.1038/nature00981

78. Nilsen H, Otterlei M, Haug T, Solum K, Nagelhus TA, Skorpen F, et al. Nuclear and mitochondrial uracil-DNA glycosylases are generated by alternative splicing and transcription from different positions in the UNG gene. Nucleic Acids Res. (1997) 25:750-5. doi: 10.1093/nar/25.4.750

79. Akbari M, Otterlei M, Pena-Diaz J, Aas PA, Kavli B, Liabakk NB, et al. Repair of U/G and U/A in DNA by UNG2-associated repair complexes takes place predominantly by short-patch repair both in proliferating and growtharrested cells. Nucleic Acids Res. (2004) 32:5486-98. doi: 10.1093/nar/gkh872

80. Kavli B, Andersen S, Otterlei M, Liabakk NB, Imai K, Fischer A, et al. B cells from hyper-IgM patients carrying UNG mutations lack ability to remove uracil from ssDNA and have elevated genomic uracil. J Exp Med. (2005) 201:2011-21. doi: 10.1084/jem.20050042

81. Esposito G, Texido G, Betz UA, Gu H, Muller W, Klein U, et al. Mice reconstituted with DNA polymerase beta-deficient fetal liver cells are able to mount a $\mathrm{T}$ cell-dependent immune response and mutate their Ig genes normally. Proc Natl Acad Sci USA. (2000) 97:1166-71. doi: 10.1073/pnas.97.3.1166

82. Wu X, Stavnezer J. DNA polymerase beta is able to repair breaks in switch regions and plays an inhibitory role during immunoglobulin class switch recombination. J Exp Med. (2007) 204:1677-89. doi: 10.1084/jem.20070756

83. Haracska L, Unk I, Johnson RE, Johansson E, Burgers PM, Prakash S, et al. Roles of yeast DNA polymerases delta and zeta and of Rev1 in the bypass of abasic sites. Genes Dev. (2001) 15:945-54. doi: 10.1101/gad.882301

84. Nair DT, Johnson RE, Prakash L, Prakash S, Aggarwal AK. DNA synthesis across an abasic lesion by yeast REV1 DNA polymerase. J Mol Biol. (2011) 406:18-28. doi: 10.1016/j.jmb.2010.12.016

85. Nelson JR, Lawrence CW, Hinkle DC. Deoxycytidyl transferase activity of yeast REV1 protein. Nature. (1996) 382:729-31. doi: 10.1038/ $382729 \mathrm{a} 0$
86. Masuda Y, Takahashi M, Fukuda S, Sumii M, Kamiya K. Mechanisms of dCMP transferase reactions catalyzed by mouse Rev1 protein. J Biol Chem. (2002) 277:3040-6. doi: 10.1074/jbc.M110149200

87. Jansen JG, Langerak P, Tsaalbi-Shtylik A, van den Berk P, Jacobs H, de Wind N. Strand-biased defect in C/G transversions in hypermutating immunoglobulin genes in Rev1-deficient mice. J Exp Med. (2006) 203:31923. doi: $10.1084 /$ jem. 20052227

88. Jansen JG, Tsaalbi-Shtylik A, Langerak P, Calleja F, Meijers CM, Jacobs $\mathrm{H}$, et al. The BRCT domain of mammalian Rev1 is involved in regulating DNA translesion synthesis. Nucleic Acids Res. (2005) 33:356-65. doi: $10.1093 /$ nar/gki189

89. Guo C, Sonoda E, Tang TS, Parker JL, Bielen AB, Takeda S, et al. REV1 protein interacts with PCNA: significance of the REV1 BRCT domain in vitro and in vivo. Mol Cell. (2006) 23:265-71. doi: 10.1016/j.molcel.2006.05.038

90. Ross AL, Sale JE. The catalytic activity of REV1 is employed during immunoglobulin gene diversification in DT40. Mol Immunol. (2006) 43:1587-94. doi: 10.1016/j.molimm.2005.09.017

91. Kano C, Hanaoka F, Wang JY. Analysis of mice deficient in both REV1 catalytic activity and POLH reveals an unexpected role for POLH in the generation of $\mathrm{C}$ to $\mathrm{G}$ and $\mathrm{G}$ to $\mathrm{C}$ transversions during Ig gene hypermutation. Int Immunol. (2012) 24:169-74. doi: 10.1093/intimm/dxr109

92. Hirota K, Yoshikiyo K, Guilbaud G, Tsurimoto T, Murai J, Tsuda M, et al. The POLD3 subunit of DNA polymerase delta can promote translesion synthesis independently of DNA polymerase zeta. Nucleic Acids Res. (2015) 43:1671-83. doi: 10.1093/nar/gkv023

93. Thientosapol ES, Sharbeen G, K.Lau KE, Bosnjak D, Durack T, Stevanovski I, et al. Proximity to AGCT sequences dictates MMR-independent versus MMR-dependent mechanisms for AID-induced mutation via UNG2. Nucleic Acids Res. (2017) 45:3146-57.

94. Krokan HE, Drablos F, Slupphaug G. Uracil in DNAoccurrence, consequences and repair. Oncogene. (2002) 21:8935-48. doi: 10.1038/sj.onc. 1205996

95. Schanz S, Castor D, Fischer F, Jiricny J. Interference of mismatch and base excision repair during the processing of adjacent U/G mispairs may play a key role in somatic hypermutation. Proc Natl Acad Sci USA. (2009) 106:5593-8. doi: 10.1073/pnas.0901726106

96. Martomo SA, Yang WW, Gearhart PJ. A role for Msh6 but not Msh3 in somatic hypermutation and class switch recombination. J Exp Med. (2004) 200:61-8. doi: 10.1084/jem.20040691

97. Martin A, Li Z, Lin DP, Bardwell PD, Iglesias-Ussel MD, Edelmann W, et al. Msh2 ATPase activity is essential for somatic hypermutation at a-T basepairs and for efficient class switch recombination. J Exp Med. (2003) 198:1171-8. doi: $10.1084 /$ jem. 20030880

98. Phung QH, Winter DB, Alrefai R, Gearhart PJ. Hypermutation in Ig V genes from mice deficient in the MLH1 mismatch repair protein. J Immunol. (1999) 162:3121-4.

99. Kim N, Bozek G, Lo JC, Storb U. Different mismatch repair deficiencies all have the same effects on somatic hypermutation: intact primary mechanism accompanied by secondary modifications. J Exp Med. (1999) 190:21-30. doi: 10.1084/jem.190.1.21

100. Ehrenstein MR, Rada C, Jones AM, Milstein C, Neuberger MS. Switch junction sequences in PMS2-deficient mice reveal a microhomologymediated mechanism of Ig class switch recombination. Proc Natl Acad Sci USA. (2001) 98:14553-8. doi: 10.1073/pnas.241525998

101. Bardwell PD, Woo CJ, Wei K, Li Z, Martin A, Sack SZ, et al. Altered somatic hypermutation and reduced class-switch recombination in exonuclease 1mutant mice. Nat Immunol. (2004) 5:224-9. doi: 10.1038/ni1031

102. Zeng X, Winter DB, Kasmer C, Kraemer KH, Lehmann AR, Gearhart PJ. DNA polymerase eta is an A-T mutator in somatic hypermutation of immunoglobulin variable genes. Nat Immunol. (2001) 2:537-41. doi: $10.1038 / 88740$

103. Krijger PH, van den Berk PC, Wit N, Langerak P, Jansen JG, Reynaud CA, et al. PCNA ubiquitination-independent activation of polymerase eta during somatic hypermutation and DNA damage tolerance. DNA Repair. (2011) 10:1051-9. doi: 10.1016/j.dnarep.2011.08.005

104. Matsuda T, Bebenek K, Masutani C, Hanaoka F, Kunkel TA. Low fidelity DNA synthesis by human DNA polymerase-eta. Nature. (2000) 404:1011-3. doi: $10.1038 / 35010014$ 
105. Rogozin IB, Pavlov YI, Bebenek K, Matsuda T, Kunkel TA. Somatic mutation hotspots correlate with DNA polymerase eta error spectrum. Nat Immunol. (2001) 2:530-6. doi: 10.1038/88732

106. Pavlov YI, Rogozin IB, Galkin AP, Aksenova AY, Hanaoka F, Rada C, et al. Correlation of somatic hypermutation specificity and A-T base pair substitution errors by DNA polymerase eta during copying of a mouse immunoglobulin kappa light chain transgene. Proc Natl Acad Sci USA. (2002) 99:9954-9. doi: 10.1073/pnas.152126799

107. Delbos F, De Smet A, Faili A, Aoufouchi S, Weill JC, Reynaud CA. Contribution of DNA polymerase eta to immunoglobulin gene hypermutation in the mouse. J Exp Med. (2005) 201:1191-6. doi: $10.1084 /$ jem.20050292

108. Schenten D, Gerlach VL, Guo C, Velasco-Miguel S, Hladik CL, White $\mathrm{CL}$, et al. DNA polymerase kappa deficiency does not affect somatic hypermutation in mice. Eur J Immunol. (2002) 32:3152-60. doi: 10.1002/ 1521-4141(200211)32:11\&lt;3152::AID-IMMU3152\&gt;3.0.CO;2-2

109. Shimizu T, Shinkai Y, Ogi T, Ohmori H, Azuma T. The absence of DNA polymerase kappa does not affect somatic hypermutation of the mouse immunoglobulin heavy chain gene. Immunol Lett. (2003) 86:265-70. doi: 10.1016/S0165-2478(03)00046-4

110. Faili A, Stary A, Delbos F, Weller S, Aoufouchi S, Sarasin A, et al. A backup role of DNA polymerase kappa in Ig gene hypermutation only takes place in the complete absence of DNA polymerase eta. J Immunol. (2009) 182:6353-9. doi: 10.4049/jimmunol.0900177

111. Roa S, Avdievich E, Peled JU, Maccarthy T, Werling U, Kuang FL, et al. Ubiquitylated PCNA plays a role in somatic hypermutation and class-switch recombination and is required for meiotic progression. Proc Natl Acad Sci USA. (2008) 105:16248-53. doi: 10.1073/pnas. 0808182105

112. Friedberg EC, Suffering in silence: the tolerance of DNA damage. Nat Rev. (2005) 6:943-53. doi: 10.1038/nrm1781

113. Shimizu T, Tateishi S, Tanoue Y, Azuma T, Ohmori H. Somatic hypermutation of immunoglobulin genes in Rad18 knockout mice. DNA Repair. (2017) 50:54-60. doi: 10.1016/j.dnarep.2016.12.008

114. Simpson LJ, Ross AL, Szuts D, Alviani CA, Oestergaard VH, Patel KJ, Sale JE. RAD18-independent ubiquitination of proliferating-cell nuclear antigen in the avian cell line DT40. EMBO Rep. (2006) 7:927-32. doi: 10.1038/sj.embor.7400777

115. Terai K, Abbas T, Jazaeri AA, Dutta A. CRL4(Cdt2) E3 ubiquitin ligase monoubiquitinates PCNA to promote translesion DNA synthesis. Mol Cell. (2010) 37:143-9. doi: 10.1016/j.molcel.2009.12.018

116. Zhang S, Chea J, Meng X, Zhou Y, Lee EY, Lee MY. PCNA is ubiquitinated by RNF8. Cell Cycle. (2008) 7:3399-404. doi: 10.4161/cc. 7.21.6949

117. Delbos F, Aoufouchi S, Faili A, Weill JC, Reynaud CA. DNA polymerase eta is the sole contributor of $\mathrm{A} / \mathrm{T}$ modifications during immunoglobulin gene hypermutation in the mouse. J Exp Med. (2007) 204:17-23. doi: 10.1084/jem.20062131

118. Sabouri Z, Okazaki IM, Shinkura R, Begum N, Nagaoka H, Tsuchimoto $\mathrm{D}$, et al. Apex 2 is required for efficient somatic hypermutation but not for class switch recombination of immunoglobulin genes. Int Immunol. (2009) 21:947-55. doi: 10.1093/intimm/dxp061

119. Stavnezer J, Linehan EK, Thompson MR, Habboub G, Ucher AJ, Kadungure $\mathrm{T}$, et al. Differential expression of APE1 and APE2 in germinal centers promotes error-prone repair and A:T mutations during somatic hypermutation. Proc Natl Acad Sci USA. (2014) 111:9217-22. doi: 10.1073/pnas.1405590111

120. Genschel J, Modrich P. Mechanism of 5'-directed excision in human mismatch repair. Mol Cell. (2003) 12:1077-86. doi: 10.1016/S1097-2765(03)00428-3

121. Maul RW, MacCarthy T, Frank EG, Donigan KA, McLenigan MP, Yang $\mathrm{W}$, et al. DNA polymerase iota functions in the generation of tandem mutations during somatic hypermutation of antibody genes. J Exp Med. (2016) 213:1675-83. doi: 10.1084/jem.20151227

122. Saribasak H, Maul RW, Cao Z, Yang WW, Schenten D, Kracker S, et al. DNA polymerase zeta generates tandem mutations in immunoglobulin variable regions. J Exp Med. (2012) 209:1075-81. doi: 10.1084/jem. 20112234
123. Schenten D, Kracker S, Esposito G, Franco S, Klein U, Murphy M, et al. Pol zeta ablation in B cells impairs the germinal center reaction, class switch recombination, DNA break repair, and genome stability. J Exp Med. (2009) 206:477-90. doi: 10.1084/jem.20080669

124. Maul RW, Saribasak H, Martomo SA, McClure RL, Yang W, Vaisman A, et al. Uracil residues dependent on the deaminase AID in immunoglobulin gene variable and switch regions. Nat Immunol. (2011) 12:70-6. doi: $10.1038 /$ ni.1970

125. Sohail A, Klapacz J, Samaranayake M, Ullah A, Bhagwat AS. Human activation-induced cytidine deaminase causes transcription-dependent, strand-biased C to U deaminations. Nucl Acids Res. (2003) 31:2990-4. doi: $10.1093 / \mathrm{nar} / \mathrm{gkg} 464$

126. Shen HM, Storb U. Activation-induced cytidine deaminase (AID) can target both DNA strands when the DNA is supercoiled. Proc Natl Acad Sci USA. (2004) 101:12997-3002. doi: 10.1073/pnas.0404974101

127. Qiao Q, Wang L, Meng FL, Hwang JK, Alt FW, Wu H. AID recognizes structured DNA for class switch recombination. Mol Cell. (2017) 67:361-373 e4. doi: 10.1016/j.molcel.2017.06.034

128. Abdouni HS, King JJ, Ghorbani A, Fifield H, Berghuis L, Larijani M. DNA/RNA hybrid substrates modulate the catalytic activity of purified AID. Mol Immunol. (2018) 93:94-106. doi: 10.1016/j.molimm.2017.11.012

129. Kim N, Storb U. The role of DNA repair in somatic hypermutation of immunoglobulin genes. J Exp Med. (1998) 187:1729-33. doi: $10.1084 /$ jem.187.11.1729

130. Storb U, Peters A, Klotz E, Kim N, Shen HM, Kage K, et al. Somatic hypermutation of immunoglobulin genes is linked to transcription. Curr Topics Microbiol Immunol. (1998) 229:11-9. doi: 10.1007/978-3-642-71984-4_2

131. Mayorov VI, Rogozin IB, Adkison LR, Gearhart PJ. DNA polymerase eta contributes to strand bias of mutations of $\mathrm{A}$ versus $\mathrm{T}$ in immunoglobulin genes. J Immunol. (2005) 174:7781-6. doi: 10.4049/jimmunol.174.12.7781

132. Unniraman S, Schatz DG. Strand-biased spreading of mutations during somatic hypermutation. Science. (2007) 317:1227-30. doi: 10.1126/science. 1145065

133. Zivojnovic M, Delbos F, Girelli Zubani G, Julé A, Alcais A, Weill JC, et al. Somatic hypermutation at A/T-rich oligonucleotide substrates shows different strand polarities in Ung-deficient or -proficient backgrounds. Mol Cell Biol. (2014) 34:2176-87. doi: 10.1128/MCB.01452-13

134. Steele EJ, Blanden RV. The reverse transcriptase model of somatic hypermutation. Philos Trans R Soc Lond Ser B Biol Sci. (2001) 356:61-6. doi: 10.1098/rstb.2000.0749

135. Steele EJ, Franklin A, Blanden RV. Genesis of the strand-biased signature in somatic hypermutation of rearranged immunoglobulin variable genes. Immunol Cell Biol. (2004) 82:209-18. doi: 10.1046/j.0818-9641.2004. 01224.x

136. Franklin A, Milburn PJ, Blanden RV, Steele EJ. Human DNA polymerase-eta, an A-T mutator in somatic hypermutation of rearranged immunoglobulin genes, is a reverse transcriptase. Immunol Cell Biol. (2004) 82:219-25. doi: 10.1046/j.0818-9641.2004.01221.x

137. Su Y, Egli M, Guengerich FP. Human DNA polymerase eta accommodates RNA for strand extension. J Biol Chem. (2017) 292:18044-18051. doi: 10.1074/jbc.M117.809723

138. Gali VK, Balint E, Serbyn N, Frittmann O, Stutz F, Unk I. Translesion synthesis DNA polymerase eta exhibits a specific RNA extension activity and a transcription-associated function. Sci Rep. (2017) 7:13055. doi: 10.1038/s41598-017-12915-1

139. Norio P, Kosiyatrakul S, Yang Q, Guan Z, Brown NM, Thomas S, Riblet R, Schildkraut CL. Progressive activation of DNA replication initiation in large domains of the immunoglobulin heavy chain locus during B cell development. Mol Cell. (2005) 20:575-87. doi: 10.1016/j.molcel. 2005.10.029

140. Guan Z, Hughes CM, Kosiyatrakul S, Norio P, Sen R, Fiering S, et al. Decreased replication origin activity in temporal transition regions. J Cell Biol. (2009) 187:623-35. doi: 10.1083/jcb.200905144

141. Demczuk A, Gauthier MG, Veras I, Kosiyatrakul S, Schildkraut $\mathrm{CL}$, Busslinger $\mathrm{M}$, et al. Regulation of DNA replication within the immunoglobulin heavy-chain locus during B cell commitment. PLoS Biol. (2012) 10:e1001360. doi: 10.1371/journal.pbio.1001360 
142. Seplyarskiy VB, Soldatov RA, Popadin KY, Antonarakis SE, Bazykin GA, Nikolaev SI. APOBEC-induced mutations in human cancers are strongly enriched on the lagging DNA strand during replication. Genome Res. (2016) 26:174-82. doi: 10.1101/gr.1970 46.115

143. Haradhvala NJ, Polak P, Stojanov P, Covington KR, Shinbrot E, Hess $\mathrm{JM}$, et al. Mutational strand asymmetries in cancer genomes reveal mechanisms of DNA damage and repair. Cell. (2016) 164:538-49. doi: 10.1016/j.cell.2015.12.050

144. Fumasoni M, Zwicky K, Vanoli F, Lopes M, Branzei D. Error-free DNA damage tolerance and sister chromatid proximity during DNA replication rely on the Polalpha/Primase/Ctf4 Complex. Mol Cell. (2015) 57:812-823. doi: 10.1016/j.molcel.2014.12.038

145. Le Q, Maizels N. Cell cycle regulates nuclear stability of AID and determines the cellular response to AID. PLoS Genet. (2015) 11:e1005411. doi: 10.1371/journal.pgen.1005411

146. Thientosapol ES, Bosnjak D, Durack T, Stevanovski I, van Geldermalsen M, Holst J, et al. SAMHD1 enhances immunoglobulin hypermutation by promoting transversion mutation. Proc Natl Acad Sci USA. (2018) 115:4921-4926. doi: 10.1073/pnas.17197 71115
147. Chabes A, Stillman B. Constitutively high dNTP concentration inhibits cell cycle progression and the DNA damage checkpoint in yeast Saccharomyces cerevisiae. Proc Natl Acad Sci USA. (2007) 104:1183-8. doi: 10.1073/pnas.0610585104

148. Bonifati S, Daly MB, St Gelais C, Kim SH, Hollenbaugh JA, Shepard C, et al. SAMHD1 controls cell cycle status, apoptosis and HIV-1 infection in monocytic THP-1 cells. Virology. (2016) 495:92-100. doi: 10.1016/j.virol.2016.05.002

149. Brenner S, Milstein C. Origin of antibody variation. Nature. (1966) 211:2423. doi: $10.1038 / 211242 \mathrm{a} 0$

Conflict of Interest Statement: The authors declare that the research was conducted in the absence of any commercial or financial relationships that could be construed as a potential conflict of interest.

Copyright (๑) 2019 Pilzecker and Jacobs. This is an open-access article distributed under the terms of the Creative Commons Attribution License (CC BY). The use, distribution or reproduction in other forums is permitted, provided the original author(s) and the copyright owner(s) are credited and that the original publication in this journal is cited, in accordance with accepted academic practice. No use, distribution or reproduction is permitted which does not comply with these terms. 